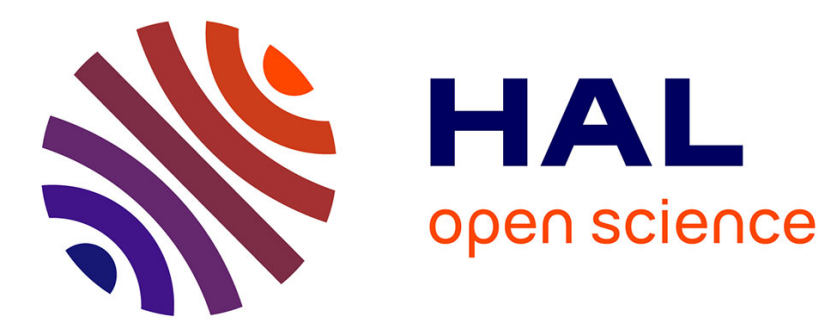

\title{
Experimental and survey-based evidences for effective biotic resistance by predators in ports
} Jean-Charles Leclerc, Frédérique Viard, Antonio Brante

\section{To cite this version:}

Jean-Charles Leclerc, Frédérique Viard, Antonio Brante. Experimental and survey-based evidences for effective biotic resistance by predators in ports. Biological Invasions, 2019, 10.1007/s10530-01902092-9 . hal-02372596

\section{HAL Id: hal-02372596 https://hal.science/hal-02372596}

Submitted on 20 Nov 2019

HAL is a multi-disciplinary open access archive for the deposit and dissemination of scientific research documents, whether they are published or not. The documents may come from teaching and research institutions in France or abroad, or from public or private research centers.
L'archive ouverte pluridisciplinaire HAL, est destinée au dépôt et à la diffusion de documents scientifiques de niveau recherche, publiés ou non, émanant des établissements d'enseignement et de recherche français ou étrangers, des laboratoires publics ou privés. 


\section{Experimental and survey-based evidences for effective biotic}

\section{resistance by predators in ports}

3

Jean-Charles Leclerc $^{1, *}$, Frédérique Viard $^{2}$, Antonio Brante ${ }^{1}$

5

6 ' $\quad$ Universidad Católica de la Santísima Concepción, Departamento de Ecología, Facultad de Ciencias,

7 Centro de Investigación en Biodiversidad y Ambientes Sustentables (CIBAS), Casilla 297, Concepción,

Chile

9 25orbonne Université, CNRS, UMR 7144 AD2M, Station Biologique de Roscoff, Place Georges Teissier,

15 Running headline: Consumptive biotic resistance in ports 


\section{Abstract}

19 Of the suite of species interactions involved in biotic resistance to species invasions, predation can

20 have complex outcomes according to the theoretical and empirical framework of community

21 ecology. In this study, we aimed to determine the likelihood of consumptive biotic resistance within

22 fouling communities in four ports of central Chile. Notably, we examined the influence of micro-

$23(>1-2 \mathrm{~mm},<1-2 \mathrm{~cm})$ and macro- $(>1-2 \mathrm{~cm})$ predators, with a particular focus on their effects on

24 non-indigenous species (NIS). Experimental and observational approaches were combined. An

25 exclusion experiment was carried out over four months to examine predator effect on the early

26 establishment of new assemblages on settlement panels. Later successional stages upon panels

27 were examined over a total of twenty-six months and supported by rapid assessment surveys in the

28 surrounding habitats. Community structure was significantly influenced by the exclusion

29 treatments. Macropredators reduced the fouling biomass and abundance, although conflicting

30 patterns emerged from the exclusion of both categories of predators. Altogether, predators reduced

31 the abundance of most NIS and cryptogenic species, some of them being only observed when the

32 two categories of predators were excluded - a pattern generally sustained over the long-term

33 dynamics in community development. Our results show an effective consumptive biotic resistance,

34 furthermore possibly dependent on predator size. Further work is however needed to determine the

35 influence of the functional diversity of natural enemies on the efficiency of biotic resistance and

36 its interplay with other biotic interactions (competition or mutualism). A comprehensive

37 understanding of these process should in turn help defining management strategies in a context of

38 habitat modification and species loss.

39 Keywords: Complementarity, Consumptive resistance, Enemy release, Exclusion experiment

40 Long-term survey, Marine infrastructure, Non-Indigenous Species, Species interactions. 
43 In ecological studies, the performance of native communities in buffering the establishment of

44 newly introduced species has been experimentally unexplored until the 1990s (Kimbro et al. 2013;

45 Levine et al. 2004; Papacostas et al. 2017), although this process caught attention much earlier

46 (Elton 1958). The biotic resistance hypothesis predicts that the establishment and spread of introduced species can fail locally in diverse communities owing to interactions with native species

48 (Bulleri et al. 2008; Lockwood et al. 2013). The most commonly explored mechanism underlying

49 biotic resistance has been competition, where a more diverse assemblages of native species is assumed to utilize resources more completely than a less diverse community (Davis et al. 2000).

51 Other mechanisms such as predation lato sensu (including herbivory and parasitism, Morin 2011)

52 and mutualism may be particularly important (Lockwood et al. 2013). Beyond regulation of prey 53 populations, predation may mediate competitive interactions and in turn affect species abundance 54 and community structure (Morin 2011). Not surprisingly then, trophic interactions studies and food 55 web theory were required to alleviate the diversity-stability debate and to understand the underlying 56 mechanisms, such as productivity, connectance, interaction strength and opportunism (Connell and 57 Ghedini 2015; Rooney and McCann 2012). Likewise, invasion ecology should benefit from a more 58 comprehensive understanding of the direct and indirect effects of multiple enemies upon introduced 59 species, especially in the framework of the biotic resistance paradigm (Caselle et al. 2018; Smith60 Ramesh et al. 2017).

In the marine realm, bioinvasions are increasing in response to expanding transportation 62 network, habitat losses and climate change (Chan et al. 2019; Giakoumi and Pey 2017; Seebens et 63 al. 2016). Extra-range dispersal of NIS involve diverse vectors (crafts and ships, marine debris, 64 cultivated and bait species) and pathways, such as mass dispersal shipping routes and physical 
65 corridors due to the 'ocean sprawl' (i.e., artificial structures built along natural shores) (e.g. Bishop

66 et al. 2017; Seebens et al. 2016). Regarding these conspicuous risks of introduction and 67 establishment of new species, the apparent resistance of particular habitats or regions to species 68 invasions is particularly meaningful to examine in order to determine the underlying ecological 69 processes (Freestone et al. 2013), and thus to build up relevant and effective management strategies 70 (Caselle et al. 2018; Dafforn et al. 2015).

Beyond alteration of species connectivity, the ocean sprawl is directly associated with habitat degradation and loss (Bishop et al. 2017). Artificial habitats, such as ports, do not surrogate 73 the diversity and community structure of neighbouring rocky reefs. These habitats constitute a 74 haven for novel species interactions - notably involving non-indigenous species (NIS) - the 75 direction and intensity of which are poorly understood (Chapman and Underwood 2011; Leclerc and Viard 2018; Rogers et al. 2016). Exclusion experiments in such habitats are fortunately flourishing and provide important insights into spatial and temporal variations in consumer effects upon fouling development (e.g. Dumont et al. 2011b; Giachetti et al. 2019; Lavender et al. 2017). Despite invasion theories which predict that a species predisposition to predation may depend on its evolutionary history (e.g. "enemy release" vs. "new association", Colautti et al. 2004; Hokkanen

81 and Pimentel 1989), there has been seldom study that separated consumer effects upon marine native species and NIS (Leclerc and Viard 2018; Rogers et al. 2016). Likewise, there is mounting

83 evidence that all predators do not equally influence fouling community development at local scales

84 (notably depending on their functional/taxonomic group and size) (Lavender et al. 2014; Osman 85 and Whitlatch 1998; Rogers et al. 2016) and yet the implications of such findings for consumptive 86 biotic resistance are so far elusive in marine systems. 
In the SE Pacific and more specifically along the Chilean coastline, the number and extent

88 of artificial structures have dramatically expanded over the last decades in order to promote economic development through shipping trade, mining and aquaculture, but also to protect coastal populations from storms and tsunamis (Aguilera 2018). In this region, shipping pathways have

91 been assumed to be responsible for the introduction of 30-38 \% of the NIS currently established 92 (Castilla and Neill 2009). A recent study comparing local and international ports along 100s km in 93 central Chile did not find any evidence that these ports differed in propagule pressure and NIS 94 abundances, suggesting a role for other introduction vectors such as aquaculture or a rapid spread 95 from international to local ports (Leclerc et al. 2018). This latter work also revealed that most NIS, 96 albeit relatively diverse, were scarce, generally restricted to cryptic micro-habitats (out of the reach 97 of large predators) and less effective in colonizing bare substrata than native taxa. In addition, 98 diverse native predators were observed but their influence (indirectly inferred by the abundance of 99 grazing marks) seemingly varied among sites. As such, the authors pointed out that biotic resistance 100 due to consumptive interactions deserved further dedicated investigation. The present study aimed to determine the influence of predators on the diversity and 102 structure of fouling communities in Chilean ports. Combining both experimental and observational 103 approaches, we gathered data from rapid assessment surveys, an exclusion experiment and a 104 community development experiment within three sites (out of four, see methods) of central Chile. 105 Exclusion experiments targeting either macro- $(>1-2 \mathrm{~cm})$ and micro-predators $(>1-2 \mathrm{~mm})$ or 106 macro-predators only (i.e., leaving only micro-predators as putative consumers) were run to (i) 107 quantify their influence on early community development, upon settlement panels and (ii) whether 108 their effects were concentrated upon specific prey categories (i.e., taxonomic and functional 109 groups, native versus non-indigenous taxa). The outcomes (i.e., targeted preys) of this short term 
110 experiment were then compared with abundance data from field surveys and from the established

111 panel community, in order to determine whether consumptive biotic resistance upon specific

112 taxa/groups is sustained over time and to give insights into other presumable indirect effects

113 (competition, facilitation) influencing the overall biotic resistance of the study communities.

115 Materials \& Methods

\section{Predator exclusion design}

A series of settlement panels (black polypropylene, $15 \times 15 \mathrm{~cm}$ ) were deployed vertically

123 upon two experimental units $(110 \times 100 \mathrm{~cm})$ made of a plastic fence $($ mesh $2.5 \times 2.5 \mathrm{~cm})$ covered

124 by a mosquito net (ca. 1-2 $\mathrm{mm}$ mesh), on two randomly selected pilings (in direct contact with the 125 bottom) separated by $20-50 \mathrm{~m}$ within each port, at ca. $-4 \mathrm{~m}$. Each unit was composed of 15 panels, 126 randomly organized as triplicates undergoing five treatments: caged, cage-control, screened, 127 screen-control and open. Cages $(20 \times 20 \times 12 \mathrm{~cm})$ were constructed from galvanized steel fence 128 (diagonal mesh of ca. $2 \mathrm{~cm}$ ), previously protected by water based-anticorrosive paint. Cage129 controls were cages lacking a roof and with two windows $(40 \times 60 \mathrm{~mm})$ cut out on the sides (Leclerc 130 and Viard 2018). Screened and screen-control treatments were respectively made of the same 131 matrix used for caged and cage-control treatments, but covered by a nylon mosquito net (1-2 mm 132 mesh). Open treatments were panels without cages. 
134 March 2018 (austral summer), a season favourable to the settlement of juveniles of many

135 invertebrate species, including NIS, in the study area (Leclerc et al. 2018) and to the maintenance

136 of the experimental units (a first trial was attempted in the previous winter but most cages were

137 damaged by wave action). To prevent flow and recruitment disruption by fouling organisms, cages

138 and meshes were cleaned every 4 weeks using a plastic brush. This cleaning frequency was chosen

139 based on previous knowledge and observations made on pilings with this type of thin material (for

140 instance, lower colonization than on floating pontoons; Leclerc et al., in prep, (Leclerc and Viard

141 2018)). It is noteworthy that at each cleaning occasion, only biofilm and a few vines (e.g.

142 Bougainvillia muscus) were observed on the fences and meshes, suggesting that the flow had been

143 properly maintained between consecutive cleaning dates (i.e., limited obstruction, JCL, pers. obs.).

144 By the end of the trial, experimental units were retrieved by divers. On land, panels were quickly

145 collected and cleared from cable tiles. A few screened cages were damaged ( 2 in Lirquén and 1 in

146 Coliumo). Because mobile predators were recorded on the panels of these screened cages, these

147 replicates were put aside. All the other panels were kept in individual plastic rubble-bags within 148 seawater tanks until being processed in the laboratory.

150 Community development upon panels and predators characterization

151 The predator exclusion experiment targeted the early community development. In order to 152 put the results into a longer term perspective, we analysed the community development upon panels 153 deployed in the field over a 26 months-period. In August 2016 (first trial) and March 2017 (second 154 trial), 20 settlement panels ( $c f$., above) were deployed upon two experimental units $(90 \times 100 \mathrm{~cm})$, 155 at two plots (pilings) per port. After 1, 3, 7, 13 and 19 months, eight panels (four at random per 156 plot) were retrieved using meshed bags, and transported within seawater to the laboratory. 
In order to complement the settlement panel datasets and to get a more comprehensive list

158 of putative macro-predators of the study communities, we used rapid assessment surveys conducted 159 by the same diver (JCL) in November 2016 and June 2017 in all localities. During 30 minutes, all 160 taxa (including fouling species and mobile taxa $>10 \mathrm{~mm}$ ) encountered were given a score of semi-

161 abundance according to the SACFOR scale (Superabundant, Abundant, Common, Frequent, 162 Occasional, Rare). These surveys were conducted between ca. - $1.5 \mathrm{~m}$ and $-5 \mathrm{~m}$, and usually over 163 the horizontal distance between the experimental plots depending on the site conformation.

\section{Data collection}

In the laboratory, panels were weighted (corrected wet mass) and then left in seawater tanks

167 until sessile fauna returned to their natural untense state. Sessile taxa (mostly fauna, see Results)

168 were identified, under a dissecting microscope, at the lowest taxonomic level possible by the same

169 observer (JCL). The same observer made at the same time a rough identification of the mobile

170 fauna, incl. micro-predators: amphipods, annelids, shrimps, crabs, likely including macro-predator

171 juveniles, were observed. To avoid edge effects, a $15 \mathrm{~mm}$ perimeter was excluded from the 172 analysis. The abundances of the sessile taxa were assessed using cover. Species cover was 173 estimated under 100 random intersection points out of 169 created between evenly spaced lengths 174 of string of quadrat within the working area $(120 \times 120 \mathrm{~mm})$. Any species identified out of these 175 intersection points was given a cover of $0.5 \%$. Species layering was taken into account, therefore 176 the total cover frequently exceeded $100 \%$. Voucher specimens were collected and preserved in $17795 \% \mathrm{EtOH}$ in order to fill in a local reference collection (cf., Leclerc et al., 2018). Taxa were 178 assigned to functional groups based upon their morphology and space occupancy as these traits 179 efficiently classify epibenthic assemblages (Woodin and Jackson 1979). Specimens were also 180 categorized according to their status as 'native', 'non-indigenous' (NIS), 'cryptogenic' or 
181 'unassigned' according to the literature and public databases (cf. Leclerc et al. 2018 and references

182 therein). The cryptogenic species, from unknown/uncertain origin, found in this study displayed a 183 cosmopolitan distribution and were potentially non-indigenous to the study area.

185 Statistical analyses

186 For the exclusion experiment, patterns in species richness, abundance and community structure 187 as well as species-specific abundances (cover, number) of relevant response variables (selected on 188 the basis of their contribution to community structure, see details below) were examined with a 189 three-way design using PERMANOVAs with 4999 permutations. Factors were 'treatment' (fixed, 1905 levels: open, cage-control, screen-control, caged and screened), 'site' (random) and 'piling' 191 (random, nested with site). Panels, cages and controls were designed to allow sessile fauna 192 colonization through settlement. However, in one site (Coronel), panel colonization was largely 193 due to migration of adult mussels (Semimytilus algosus) from the edges of the experimental units 194 - a behaviour strongly limited by cages. Settlement and migration of sessile fauna were thus 195 confounded in this site, which we thus excluded from the analyses. By including the blocking term 196 'piling', part of the total variance was attributed to differences between blocks, thereby reducing 197 the residual unexplained variation (Quinn and Keough 2002). The lowest interaction term 198 'treatment $\times$ piling (site)' was however excluded from the main model for two reasons. Firstly, a 199 few screened replicates were damaged and thus excluded from the analyses. The number of 200 replicates was then too small to robustly test for a possible interaction between treatments and 201 pilings. Secondly, and more importantly, with two pilings per site, pairwise comparisons for the 202 most important two-way interaction 'site $\times$ treatment' (see Results) were limited to a single degree 203 of freedom for each denominator (vs. nine den. d.f., when excluded) and thus could not be made 204 (Anderson et al. 2008). The results of the analyses based on the full model are provided in Table 
S4, with discussions about their implications on spatial variability in biotic resistance. Univariate

206 analyses were based on Euclidean distance matrices (analogous to the traditional ANOVA)

207 whereas multivariate analyses were based on Bray-Curtis similarity matrices generated from either

208 raw or transformed data. In the case of univariate analyses of the cover and number of individuals,

209 response variables were selected upon their within-site contribution to multivariate structure

210 (SIMPER) at a cut-off level of $90 \%$ within at least one treatment. For these response variables, a

211 minimal occurrence of three within at least one Treatment $\times$ Site was considered. Otherwise, the

212 corresponding site was dropped off from the analysis. The homogeneity in univariate or

213 multivariate dispersion was checked among the levels of the interaction term Site $\times$ Treatment

214 using PERMDISP (Anderson et al. 2008). In most cases, no transformation allowed

215 homoscedasticity to be achieved in univariate data, therefore analyses were run on untransformed

216 data (Underwood 1997).

217 As for the long-term survey, patterns in community assembly were examined, within each site,

218 with a three-way design including the factors 'trial' (random, 2 levels: $1^{\text {st }}$ vs $2^{\text {nd }}$ ), 'piling' (random,

219 nested within trial) and 'age' (fixed, 5 levels: 1, 3, 7, 13, 19 months). When appropriate,

220 PERMANOVAs were followed by pairwise comparisons and $P$-values were estimated using a

221 Monte Carlo procedure. To make these pairwise tests possible for the most relevant interaction

222 (age $\times$ trial, see Results), the lowest interaction term (age $\times$ piling (trial)) had to be excluded from

223 the model (increasing the degrees of freedom of each denominator from 1 to 13).

224 Univariate analyses were performed either on all variables combined (including unassigned 225 taxa), natives, cryptogenics or NIS. For all multivariate data, PERMANOVA results were 226 supported by ordination using principal coordinate (PCO) analyses and the main taxa or abiotic 227 variables (e.g., bare surface, grazing marks, dead biota) explaining differences among treatments 228 were identified according to their contribution to PCO axes (Anderson et al. 2008). The respective 
229 contributions of specific variables to community structure (SIMPER analyses) in each level of the 230 exclusion experiment and of the field survey were determined and considered throughout. All 231 analyses were performed using PRIMER 7 (Anderson et al. 2008).

233 Results

234 Diversity of native and non-indigenous sessile taxa across the study ports

235 Across sites, a total of 56 sessile taxa were identified upon settlement panels used in the 236 exclusion experiment (4 months), largely dominated by fauna (48 taxa). These records included 11 237 non-indigenous and 11 cryptogenic species, of which 4 NIS and 2 cryptogenic taxa were 238 exclusively found under predator exclusion (Table S1). Over the panel community assembly survey 239 (26 months), a similar number of sessile taxa was observed (60 taxa), including 8 NIS and 13 240 cryptogenic species, of which only 1 NIS and 2 cryptogenic species were not observed during the 2414 months of the exclusion experiment (Table S1). Complete lists and species authorities are 242 provided for sessile taxa in Table S1.

244 Macro-predators reported in the study localities are mostly native

Diverse macro-predators were identified across sites (35 taxa), third of which locally

246 classified as frequent to abundant (Table S2, Figure S5). Of these predators, a total of 18 taxa were 247 observed upon experimental structures by the end of the experiment (Table S2). The vast majority 248 of them (31 taxa; 89\%) were native taxa while the four others were unassigned. Locally dominant 249 predators were the native sea urchins Arbacia dufresnii and Tetrapygus niger in Lirquén, the sea 250 snail Tegula euryomphala and the sea star Patiria chilensis in Coliumo as well as the barnacle 251 shell-dwelling fish Hypsoblennius sordidus in San Vicente, whereas species commonly found 
across all locations were highly mobile crabs such as Romaleon setosum, Cancer plebejus and

253 Taliepus dentatus.

Exclusion treatments influence the fouling community development

Exclusion treatments significantly affected community structure over the four months of

257 the exclusion experiment, across all study sites (Table 1, Table 2, and Table S4). Caged and 258 screened treatments differed from each other, and from all other treatments (Table 1). As compared 259 to cage-control, the caged treatment (i.e., macro-predators exclusion) resulted in fouling 260 assemblages reaching significantly greater biomass (Fig. 1A), and occupying more space in two of 261 three sites (, Fig 1B-C). In contrast, the full exclusion of both macro- and micro-predators (screened 262 treatment versus screen-control) led to variable results among sites (Fig. 1). In particular, the 263 biomass increased significantly in Coliumo only (Fig. 1A). In addition, surprisingly, the screening 264 negatively affected both the biomass (Fig. 1A) and the occupied space (Fig. 1C), concomitantly to 265 an increase in bare space (Fig. 1B), in San Vicente. This later result suggested that the recruitment 266 may have been limited locally by the complete envelopment of panels with the thin mesh used.

Taxa-specific responses to predator exclusion

The exclusion performed had an effect upon species richness, but the outcomes were ambiguous considering all taxa (Table 2, Table S4, Fig. 1D). Interestingly, only the non-indigenous

271 species richness was influenced by the exclusion experiment (i.e., native and cryptogenic richness 272 were not affected Table 2, Table S4 Fig. 2A-C). As mentioned above, it is noteworthy that $27 \%$ of 273 the NIS and cryptogenic species were recorded only when predators were excluded (Table S1). As 274 compared to open treatment, NIS richness was greater under macro-predators exclusion (i.e., caged 275 treatment) in Lirquén and Coliumo (Fig. 2A-B, Fig. S6). Micro- and macro-predators exclusion 
276 (i.e., screen treatment) reduced NIS richness in all sites (Fig. 2A-C), though there may have been a screening effect in San Vicente (Fig. S6).

Irrespective of the group of taxa considered, total species abundances (covers) were affected by the exclusion experiment, though patterns differed among sites ('site $\times$ treatment' interactions, Table 2, Fig. 2A-C, see also Table S4 and Fig. S6). Overall, predator exclusion increased the cover

281 of either NIS, cryptogenic taxa or both in the three sites (Fig. 2, Fig. S6). Altogether, the more 282 drastic biotic resistance due to predation was observed in Lirquén, where macro- and micro283 predator exclusions respectively led to $73 \%$ and $21 \%$ increases in NIS cover (Fig. 2A, Fig. S6). 284 According to the principal component analysis (PCO, Fig. 2A), the respective effects of macro285 and micro-predators could be responsible of ca. 56\% (cf., ordination along axis 1 ) and 16\% (axis 286 2) of variation in community structure in Lirquén. Examining the variables correlated to the 287 different treatments suggests species-specific responses to predation across sites (Fig. 2A-C), 288 which were further scrutinized by univariate analyses (Table S5, summarized in Fig. 3). Site289 specific effects of treatments were detected on 3 natives (18\%), 2 cryptogenics (18\%) and 5 NIS 290 (45\%). The strongest biotic resistance played by macro-predators was observed in Lirquén, where 2916 to 10 fold-reduction in the cover of colonial NIS, such as Bougainvillia muscus and Bugulina 292 flabelatta, were observed. In contrast, the effect of macro-predators was mainly concentrated upon 293 native barnacles (up to 4 fold-reduction) in San Vicente. Along with total cover and biomass 294 reduction mentioned above (Fig. 1), exclusion of micro- and macro-predators led to an unexpected 295 decrease in the cover of Balanus laevis in two sites and Amathia cf. gracilis in one of them (Fig. 296 3), suggesting that the full screened caged locally limited their recruitments, especially in San 297 Vicente where the bare surface was greater in this treatment compared to the others. Nonetheless, 298 the full predator exclusion had clearer effects (according to pairwise tests) on the abundance of 299 diverse non-indigenous and cryptogenic species, such as the bryozoans Bugula neritina, Exochella 
sp. nov., and three ascidians: Corella eumyota, Ciona robusta, and Diplosoma listerianum - the

301 latter two species being virtually absent from treatments exposed to predators in Lirquén and 302 Coliumo, respectively (cf. infinite fold-change values, Fig. 3).

\section{Panel community changes over time and under predation}

Regarding the long-term settlement panel survey, the deployment date resulted in contrasting community development (significant two way-interaction "Trial $\times$ Age") in Lirquén (Pseudo-F4,68 $=14.04, P<0.001$, Fig. 4A), Coliumo (Pseudo- $F_{4,68}=9.69, P<0.001$, Fig. 4B) and

310 since the deployment (pairwise tests: $1 \neq 3 \neq 7 \neq 13 \neq 19$ months with $P_{\text {MC }}$ values ranging from $<$

3110.001 to 0.01 ). In all study sites, the first axis of the principal coordinate analyses - respectively

312 responsible of 34.0, 39.3 and $30.0 \%$ of the total variation in Lirquén (Fig. 4A), Coliumo (Fig. 4B)

313 and San Vicente (Fig. 4C) - illustrated the overall pattern of development of the panel communities

314 from 1 month (dominated by bare surface, on the left in Fig. 4) to 19 months (dominated by native 315 and a few cryptogenic species, on the right in Fig. 4).

Of the seven NIS that contributed to the multivariate structure in the exclusion experiment

317 and were affected by predators (Fig. 2 and above), only two contributed to the long term community 318 dynamics using the same criteria $(r>0.5)$ : Bougainvillia muscus in Lirquén and Exochella sp. nov. 319 in Coliumo. It is noteworthy that in the very same sites, these two species were also the main NIS 320 contributors to the community structure under predator influence after 4 months of the exclusion 321 experiment (9.8 and $28.4 \%$ of total similarity, respectively, Fig. 3). In Lirquén, the maximal 322 contributions of $B$. muscus to the community structure were observed on 3 months-old panels from 323 the first trial (29.7\%, SIMPER analyses) and 7 months-old panels from the second one (40.9\%, 
324 axis 2 on Fig. 4A), respectively sampled at the same period (spring) of two consecutive years

325 (November 2016 and October 2017). In this site, the cumulated contribution of other NIS ranged 326 from $0 \%$ (12 months- trial 1) to $11.3 \%$ (12 months - trial 2) due to occasional emergence of 327 Bugulina flabelatta and Hydractinia sp. In Coliumo, maximal contributions of Exochella sp. nov. 328 were observed after $13(26.0 \%)$ and 7 months (15.7\%) of the first and second trials, respectively 329 (Fig. 4B). In this site, the cumulated contribution of other NIS remained $<3 \%$ all over the survey. 330 Likewise, it is noteworthy that Exochella sp. nov. contributed up to $15.5 \%$ of the community 331 structure in San Vicente on one occasion (7 months - second trial) while the cumulated contribution 332 of all other NIS never exceeded $2 \%$ in this site. In parallel, the cumulated contribution of native 333 species generally increased over community development: $60-70 \%$ at the end of the first trial and $33428-31 \%$ at the end of the second one - when the contribution of either cryptogenic species (e.g. 335 Clytia linearis in Lirquén, Amphisbetia operculata in San Vicente) or the bare space (in Coliumo) 336 was locally important.

\section{Discussion}

While similar numbers of sessile taxa were observed during the short-term exclusion and

341 the long-term panel experiments, a greater number of non-indigenous species (NIS) was observed 342 upon settlement panels after the four months-duration of the exclusion experiment than over the 343 twenty-six months of the colonization survey, during which the panels were left exposed to 344 predators. Overall, the predation affected the early stage of community development. Micro- and 345 macro-predators together reduced the abundance of most NIS and cryptogenic species, of which 346 six taxa were only recorded under predator exclusion. This result, associated with the poor 
contribution of NIS to the community structure observed over more than two years of colonization

348 experiment, strongly suggests consumptive biotic resistance in the study systems.

\section{Towards novel natural enemies}

Besides the enemy release hypothesis which is the foundation of invasive species management by biological control, the new association principle emerged as a framework where biocontrol capitalizes on consumptive and "native" biotic resistance (Colautti et al. 2004; Hokkanen and Pimentel 1989). Such approach does not involve the introduction of a new species, albeit a natural enemy, and could thus avoid dramatic drawbacks (Elton 1958; Pearson and Callaway 2003). The new association principle stands on the hypothesis that a NIS is a naive prey/host, thus likely less efficient to defend itself against a novel predator/enemy.

In our exclusion experiment, all non-indigenous (and cryptogenic) ascidians were affected by predators in terms of cover and number of individuals whereas the native ascidians did not

360 virtually suffer from any type of predators, except Pyura chilensis in Coliumo (Fig. 2, 3). This 361 pattern was sustained over the long term survey where the native ascidian P. chilensis progressively 362 became one of the dominant space occupiers in the other sites, i.e. Lirquén (cover: $20.6 \pm 39.2 \%$ 363 after 18 months, pooled for trials \pm SD) and San Vicente $(54.1 \pm 46.8 \%)$, whereas non-indigenous 364 ascidians remained virtually absent upon panels (Fig. 4) - other than rare records of Ciona robusta 365 juveniles in Lirquén.

While predators can efficiently regulate post-settlement survival of ascidians, they can also

367 be quite selective (Nydam and Stachowicz 2007; Osman and Whitlatch 1995; Rius et al. 2014). In

368 New England, both micro-gastropods Cotonopsis lafresnayi and Astyris lunata limited the survival 369 of various non-indigenous or native ascidian recruits, such as Botryllus schlosseri and Diplosoma 370 sp., although Botrylloides diegensis was generally avoided (Osman and Whitlatch 1995). In 
371 addition, traits that facilitates rapid colonization are often accompanied by costs to competitive 372 advantage, such as defense against predators (Papacostas et al. 2017). As it grows, P. chilensis 373 develops a thick cellulosic tunic and resist attacks from most local predators in northern Chile 374 (Dumont et al. 2011a). Although other possible defense mechanisms may be involved (e.g. 375 Stoecker 1980), non-indigenous and fleshy ascidians (e.g., Ciona robusta) were herein apparently more naive to predation than their native counterpart, and thus not released from their new enemies.

\section{Consumptive biotic resistance might vary according to predator diversity}

Although outcomes vary among habitats, the body of knowledge accumulated in terrestrial systems generally supports the hypothesis that the more diverse are natural enemies, the more likely

381 they are to control pests (Letourneau et al. 2009). In the framework of the complementarity model, 382 these previous results also suggest that additive (e.g., synchrony) and synergistic (e.g., facilitation) 383 effects among enemies can be stronger than antagonistic effects (e.g., due to intraguild predation) 384 at high richness. Notwithstanding all emergent implications of such finding for biotic resistance, 385 the influence of predator diversity upon marine invaders has so far seemingly been generally overlooked (Byrnes and Stachowicz 2009; Dumont et al. 2011b for multiple-predator experiments

387 in fouling communties; but see Nydam and Stachowicz 2007). Our caging experiment showed that macro-predators were responsible for a sharp reduction in abundance of the introduced vine

389 hydrozoans (e.g., Bougainvillia) and tree-like bryozoans (e.g., Bugulina), in two of the three study 390 sites. While this pattern is consistent with results from previous studies (Dumont et al. 2011b; 391 Osman and Whitlatch 1998), further work would be needed to separate the effects of predator 392 categories and to determine their interactions upon these focal invaders. Indeed, micro-predators 393 could not be excluded without excluding also macro-predators. In addition, screening may have 394 locally limited the recruitment of some taxa (as suggested by the variations of bare surface in San 
395 Vicente). Even so, we clearly observed a collapse of non-indigenous ascidians in the presence of 396 micro-predators (i.e., in all treatments except screened) in every study sites. Because they 397 presumably forage on different preys (and possibly on different life stages, Dumont et al. 2011a; 398 Rius et al. 2014), it may be worth scrutinizing whether micro- and macro-predator effects are 399 complementary at the assemblage level. This aspect may be critical for the biotic resistance in the 400 study area, with regards to the non-indigenous status of most of these preys and their poor 401 contribution to community structure over long-term community development and in established 402 communities. A thorough examination of the associated food web would be needed to examine 403 further this hypothesis which could have implications for impact mitigation and NIS establishment 404 management strategies (Smith-Ramesh et al. 2017).

Biotic resistance is amongst the main targeted ecological services of eco-engineering in the 406 context of ocean sprawl. Promoting the local abundance of invader-enemies seems a promising 407 avenue (Bishop et al. 2017; Dafforn et al. 2015), as our results also mirror. The outcomes of 408 consumptive biotic resistance may however be particularly conflicting in realistic food webs, 409 especially interacting with species exploitation (Caselle et al. 2018). Both macro-predators (all 410 crabs identified) and native sessile taxa (incl. ascidians, barnacles and mussels) are fished in the 411 study region, including within ports. One can thus wonder whether the concomitant regional 412 changes in habitats (ocean sprawl, e.g. Aguilera 2018) and fisheries (Andreu-Cazenave et al. 2017) 413 may interact and to which extent it might decrease the biotic resistance herein reported - hypothesis 414 that could be addressed through further experimental and modelling approaches.

\section{Predator escapes and maintenance of discrete invader populations}


419 constrained the cover of the introduced hydrozoan Bougainvillia muscus in Lirquén, they also 420 liberated 10-fold as much bare surface (Fig. 3) available to colonization, notably by colonial species 421 in place. Over the long term survey, Bougainvillia muscus consistently bloomed over two 422 subsequent springs (Fig. 4). Whether it was due to specific invader traits (e.g. phenology in 423 reproduction and/or vegetative growth) or temporal variability in predator effects - here likely 424 mainly due to the native sea urchin Arbacia dufresnii (Leclerc et al. 2018), our results suggest that 425 biotic resistance may have complex dynamics in fluctuating environments (Stachowicz and Byrnes 426 2006). In the recently constructed jetty of Coliumo, where the bryozoan Exochella sp. nov. has 427 been recorded for the first time within the study region (in March 2017, Leclerc et al. 2018), none 428 of the exclusion treatments affected its abundance. This species became one of the dominant space429 occupiers on well-developed panel assemblages (7-13 months) and established communities in 430 surrounding habitats (Table S3). After a first record in September 2017, Exochella sp. nov. also 431 contributed substantially to community structure in San Vicente, where the species apparently met 432 at least one efficient enemy - likely absent from Coliumo - among micro-predators (Fig. 3). 433 Although both our experiments suggest that the proliferation of this species may be limited locally 434 by consumptive and/or competitive biotic resistance, they also suggest that none of these processes 435 could have prevented its establishment. Besides, Exochella sp. nov. was also found as epibiont of 436 Crepipatella fecunda and Balanus laevis, the dominant space occupiers at Coliumo in older 437 assemblages (19 months, Fig. 4), suggesting that, even facultative, mutualistic interactions could 438 impede biotic resistance processes over community assembly (Bulleri et al. 2008).

439 It is finally worth emphasizing that even non-indigenous ascidians, which experienced 440 severe predation pressure on pilings at the depth investigated, were occasionally observed as few 441 individuals or colonies (Table S3, Fig. S5) in diverse micro-habitats (ropes, buoys, cavities, jetty 442 stairwells), likely out of the reach of most predators (Dumont et al. 2011a; Rogers et al. 2016). As 
443 our full model also suggested, exclusion treatments could have contrasting effects across pilings

444 on community structure and on a few response variables (Table S4). Further work would be

445 necessary to disentangle between within site-variability in predation and propagule pressures,

446 among other confounding factors. While drastic abundance reduction can mitigate both the

447 negative effects an invader may have on a focal habitat and its probability of spread (Levine et al.

448 2004), our results altogether suggest that, across multiple scales, both spatial and temporal

449 variability in biotic resistance may provide invaders with escape opportunities to establish discrete

450 and viable populations.

In conclusion, our experimental study showed that the abundance of most NIS was reduced 453 under predation within the study region. Moreover, some NIS were only recorded when predators 454 were excluded. In light of a two-year survey of panel colonization and field censuses, our results 455 suggest that this consumptive biotic resistance is sustainable. Further work is however needed to 456 determine whether this predation effect also influences biotic interactions (competition, mutualism) 457 among fouling species. Our study also suggests some complementarity among predator categories 458 (here according to their size). Unraveling local food webs and predator functions in urban areas 459 might be helpful to develop NIS management strategies. 


\section{Authors' contributions}

462 JCL, FV and AB conceived the idea and designed the study. JCL designed the methodology, 463 collected the data and led the writing of the manuscript. FV and AB significantly contributed to 464 manuscript writing and critical review.

\section{Acknowledgements}

467 We are grateful to M Altamirano, R Reed, O Marin and I Hinojosa for diving assistance, J Martínez 468 and J Cruz for sailing assistance and to B Pedreros, S Morocco Escobar, A Araya, V Molina, E 469 Fernández, P Valenzuela and N Cofré and the CIBAS institute for help with logistics in the study 470 sites. We also thank D Gordon and for help with Exochella identification. The manuscript benefited 471 from the valuable feedback of two anonymous reviewers. JCL further thanks the Centre IDEAL 472 (Investigación Dinámica de Ecosistemas Marinos de Altas Latitudes, Universidad Austral de Chile) 473 for kind hospitality over the manuscript writing. AB was supported by a FONDECYT grant, $474 \quad \mathrm{~N}^{\circ} 1170598$. JCL was funded by a FONDECYT postdoctoral fellowship $\mathrm{N}^{\circ} 3160172$.

476 Data accessibility

477 Most of the data are provided in the supplementary material associated with the manuscript. 478 Detailed data are available from the corresponding author upon reasonable request. 


\section{References}

Aguilera MA (2018) Artificial defences in coastal marine ecosystems in Chile: Opportunities for spatial planning to mitigate habitat loss and alteration of the marine community structure. Ecological Engineering 120: 601-610

Anderson MJ, Gorley RN and Clarke KR (2008) PERMANOVA+ for PRIMER: Guide to Software and Statistical Methods. PRIMER-E: Plymouth UK.

Andreu-Cazenave M, Subida MD and Fernandez M (2017) Exploitation rates of two benthic resources across management regimes in central Chile: Evidence of illegal fishing in artisanal fisheries operating in open access areas. PLOS ONE 12: e0180012

Bishop MJ, Mayer-Pinto M, Airoldi L, Firth LB, Morris RL, Loke LH, Hawkins SJ, Naylor LA, Coleman RA and Chee SY (2017) Effects of ocean sprawl on ecological connectivity: impacts and solutions. Journal of Experimental Marine Biology and Ecology 492: 7-30

Bulleri F, Bruno JF and Benedetti-Cecchi L (2008) Beyond competition: incorporating positive interactions between species to predict ecosystem Invasibility. PLoS Biol 6: e162

Byrnes JE and Stachowicz JJ (2009) The consequences of consumer diversity loss: different answers from different experimental designs. Ecology 90: 2879-2888

Caselle JE, Davis K and Marks LM (2018) Marine management affects the invasion success of a non-native species in a temperate reef system in California, USA. Ecology letters 21: 4353

Castilla JC and Neill PE (2009) Marine bioinvasions in the Southeastern Pacific: status, ecology, economic Impacts, conservation and management. In: Rilov $\mathrm{G}$ and Crooks J (eds) Biological Invasions in Marine Ecosystems, pp 439-457, Springer Berlin Heidelberg

Chan FT, Stanislawczyk K, Sneekes AC, Dvoretsky A, Gollasch S, Minchin D, David M, Jelmert A, Albretsen J and Bailey SA (2019) Climate change opens new frontiers for marine species in the Arctic: Current trends and future invasion risks. Global change biology 25: $25-38$

Chapman MG and Underwood AJ (2011) Evaluation of ecological engineering of "armoured" shorelines to improve their value as habitat. Journal of Experimental Marine Biology and Ecology 400: 302-313

Colautti RI, Ricciardi A, Grigorovich IA and MacIsaac HJ (2004) Is invasion success explained by the enemy release hypothesis? Ecology Letters 7: 721-733

Connell SD and Ghedini G (2015) Resisting regime-shifts: the stabilising effect of compensatory processes. Trends in Ecology \& Evolution 30: 513-515

Dafforn KA, Glasby TM, Airoldi L, Rivero NK, Mayer-Pinto M and Johnston EL (2015) Marine urbanization: an ecological framework for designing multifunctional artificial structures. Frontiers in Ecology and the Environment 13: 82-90

Davis MA, Grime JP and Thompson K (2000) Fluctuating resources in plant communities: a general theory of invasibility. Journal of Ecology 88: 528-534

Dumont C, Gaymer C and Thiel M (2011a) Predation contributes to invasion resistance of benthic communities against the non-indigenous tunicate Ciona intestinalis. Biological invasions 13: 2023-2034

Dumont CP, Harris LG and Gaymer CF (2011b) Anthropogenic structures as a spatial refuge from predation for the invasive bryozoan Bugula neritina. Marine Ecology Progress Series 427: 95-103

Elton CS (1958) The ecology of invasions by plants and animals. Methuen, London 18 
Freestone AL, Ruiz GM and Torchin ME (2013) Stronger biotic resistance in tropics relative to temperate zone: effects of predation on marine invasion dynamics. Ecology 94: 13701377

Giachetti CB, Battini N, Bortolus A, Tatián M and Schwindt E (2019) Macropredators as shapers of invaded fouling communities in a cold temperate port. Journal of Experimental Marine Biology and Ecology 518: 151177

Giakoumi S and Pey A (2017) Assessing the effects of marine protected areas on biological invasions: a global review. Frontiers in Marine Science 4: 49

Hokkanen HMT and Pimentel D (1989) New associations in biological control: theory and practice. The Canadian Entomologist 121: 829-840

Kimbro DL, Cheng BS and Grosholz ED (2013) Biotic resistance in marine environments. Ecology Letters 16: 821-833

Lavender JT, Dafforn KA, Bishop MJ and Johnston EL (2017) An empirical examination of consumer effects across twenty degrees of latitude. Ecology 98: 2391-2400

Lavender JT, Dafforn KA and Johnston EL (2014) Meso-predators: A confounding variable in consumer exclusion studies. Journal of Experimental Marine Biology and Ecology 456: 26-33

Leclerc J-C, Viard F, González Sepúlveda E, Diaz C, Neira Hinojosa J, Pérez Araneda K, Silva F and Brante A (2018) Non-indigenous species contribute equally to biofouling communities in international vs local ports in the Biobío region, Chile. Biofouling 34: 784-799

Leclerc JC and Viard F (2018) Habitat formation prevails over predation in influencing fouling communities. Ecology and evolution 8: 477-492

Letourneau DK, Jedlicka JA, Bothwell SG and Moreno CR (2009) Effects of natural enemy biodiversity on the suppression of arthropod herbivores in terrestrial ecosystems. Annual Review of Ecology, Evolution, and Systematics 40: 573-592

Levine JM, Adler PB and Yelenik SG (2004) A meta-analysis of biotic resistance to exotic plant invasions. Ecology letters 7: 975-989

Lockwood JL, Hoopes MF and Marchetti MP (2013) Invasion ecology. John Wiley \& Sons

Morin PJ (2011) Predation and Communities: Empirical Patterns. Community Ecology, pp 90119, John Wiley \& Sons, Ltd

Nydam M and Stachowicz JJ (2007) Predator effects on fouling community development. Marine Ecology Progress Series 337: 93-101

Osman R and Whitlatch R (1995) Predation on early ontogenetic life stages and its effect on recruitment into a marine epifaunal community. Marine Ecology Progress Series 117: $111-126$

Osman RW and Whitlatch RB (1998) Local control of recruitment in an epifaunal community and the consequences to colonization processes. Hydrobiologia 375: 113-123

Papacostas KJ, Rielly-Carroll EW, Georgian SE, Long DJ, Princiotta SD, Quattrini AM, Reuter KE and Freestone AL (2017) Biological mechanisms of marine invasions. Marine ecology Progress Series 565: 251-268

Pearson DE and Callaway RM (2003) Indirect effects of host-specific biological control agents. Trends in Ecology \& Evolution 18: 456-461

Quinn GP and Keough MJ (2002) Experimental design and data analysis for biologists. Cambridge University Press

Rius M, Potter EE, Aguirre JD and Stachowicz JJ (2014) Mechanisms of biotic resistance across complex life cycles. Journal of Animal Ecology 83: 296-305 
Rogers TL, Byrnes JE and Stachowicz JJ (2016) Native predators limit invasion of benthic invertebrate communities in Bodega Harbor, California, USA. Marine Ecology Progress Series 545: 161-173

Rooney N and McCann KS (2012) Integrating food web diversity, structure and stability. Trends in ecology \& evolution 27: 40-46

Seebens H, Schwartz N, Schupp PJ and Blasius B (2016) Predicting the spread of marine species introduced by global shipping. Proceedings of the National Academy of Sciences of the United States of America 113: 5646-5651

Smith-Ramesh LM, Moore AC and Schmitz OJ (2017) Global synthesis suggests that food web connectance correlates to invasion resistance. Global change biology 23: 465-473

Stachowicz JJ and Byrnes JE (2006) Species diversity, invasion success, and ecosystem functioning: disentangling the influence of resource competition, facilitation, and extrinsic factors. Marine Ecology Progress Series 311: 251-262

Stoecker D (1980) Chemical defenses of ascidians against predators. Ecology 61: 1327-1334

Underwood AJ (1997) Experiments in ecology: their logical design and interpretation using analysis of variance. Cambridge University Press, Cambridge, UK

Woodin S and Jackson J (1979) Interphyletic competition among marine benthos. American Zoologist 19: 1029-1043 
593 Table 1. Results of PERMANOVA test for differences in fouling community structure among 594 levels of the main factors (site and exclusion) and their interaction (PERMDISP $\mathrm{T} \times \mathrm{S}: F_{14,72}=$ $595 \quad 6.587, P<0.001)$. Post-hoc pairwise tests are summarized.

\begin{tabular}{llcccc}
\hline Factor & df & SS & MS & Pseudo- $F$ & $P$ \\
\hline Site $=$ S & 2 & 123510 & 61756.0 & 25.890 & $<0.001$ \\
Plot (Site) $=$ P & 3 & 7161 & 2387.0 & 4.4730 & $<0.001$ \\
Treatment $=$ T & 4 & 23011 & 5752.8 & 1.571 & 0.114 \\
T x S & 8 & 30522 & 3815.2 & 6.628 & $<0.001$ \\
Res & 69 & 36824 & 533.7 & & \\
\hline
\end{tabular}

\section{Pairwise tests:}

Lirquén: $\quad \mathrm{Op}=\mathrm{CC}=\mathrm{SC} \neq \mathrm{Cag} \neq \mathrm{Scr}$

Coliumo: $\quad \mathrm{Op}=\mathrm{CC}=\mathrm{SC} \neq \mathrm{Cag} \neq \mathrm{Scr}$

San Vicente: $\quad \mathrm{Op}=\mathrm{CC}=\mathrm{SC} \neq \mathrm{Cag} \neq \mathrm{Scr}$

599 Table 2. Results of PERMANOVA tests for differences in response variables among levels of the 600 main factors and their interaction. Transformations (Transf.) and PERMDISP tests $(\mathrm{T} \times \mathrm{S})$ are 601 summarized. ${ }^{\text {ns. }}$ non-significant at $\alpha=0.05, *: P<0.05, * *: P<0.01, * * *: P<0.001$.

\begin{tabular}{|c|c|c|c|c|c|c|}
\hline \multirow{3}{*}{ Response variable } & \multirow{3}{*}{ Transf. } & \multirow{2}{*}{\multicolumn{4}{|c|}{ PERMANOVA Factor $($ df. total $=86)$}} & \multirow{3}{*}{ PERMDISP } \\
\hline & & & & & & \\
\hline & & Site $=$ S (2) & Plot $($ Site $)=P(3)$ & Treatment $=\mathrm{T}(4)$ & $\mathrm{T} \times \mathrm{S}(8)$ & \\
\hline Community structure & SqRT & $25.890 * * *$ & $4.473 * * *$ & $1.571^{\mathrm{ns}}$ & $6.628 * * *$ & $* * *$ \\
\hline Biomass (g) & None & $38.703 * * *$ & $1.169^{\text {ns }}$ & $1.324^{\mathrm{ns}}$ & $10.394 * * *$ & ns \\
\hline Bare surface $(\%)$ & None & $439.370 * * *$ & $0.191^{\mathrm{ns}}$ & $1.281^{\mathrm{ns}}$ & $9.897 * * *$ & $* * *$ \\
\hline \multicolumn{7}{|l|}{ Abundances (\%) } \\
\hline All & None & $50888.0 * * *$ & $0.001^{\mathrm{ns}}$ & $1.537^{\mathrm{ns}}$ & $8.649 * * *$ & ns \\
\hline Native & None & $2129.9^{* * *}$ & $0.1934^{\mathrm{ns}}$ & $1.577^{\mathrm{ns}}$ & $12.189 * * *$ & $* * *$ \\
\hline Cryptogenic & FoRT & $6.360^{\mathrm{ns}}$ & $3.914^{*}$ & $0.174^{\mathrm{ns}}$ & $5.408 * * *$ & $\mathrm{~ns}$ \\
\hline NIS & None & $53.350 *$ & $1.523^{\mathrm{ns}}$ & $3.031^{\mathrm{ns}}$ & $4.434 * * *$ & $* * *$ \\
\hline \multicolumn{7}{|l|}{ Richness S } \\
\hline All & None & $7.001 *$ & $4.732 * *$ & $1.168^{\mathrm{ns}}$ & $2.814^{*}$ & ns \\
\hline Native & None & $7.966^{\mathrm{ns}}$ & $1.955^{\mathrm{ns}}$ & $2.316^{\mathrm{ns}}$ & $1.557^{\mathrm{ns}}$ & ns \\
\hline Cryptogenic & SqRT & $0.389^{\text {ns }}$ & $11.300 * * *$ & $0.411^{\mathrm{ns}}$ & $0.855^{\mathrm{ns}}$ & ns \\
\hline NIS & None & $8.658 * * *$ & $7.220 * * *$ & $4.771 *$ & $2.917 * *$ & ns \\
\hline
\end{tabular}


606 Figure 1. Biomass (A), bare surface cover (B), occupied cover (C) and species richness (D) on 607 experimental panels across treatments and sites. Upper letters indicate differences among 608 treatments within each study site.

610 Figure 2. Community structure (principal coordinate analysis, left panels), richness and 611 abundances (right panels) of native (blue), cryptogenic (orange) and non-indigenous taxa (red) 612 across treatments in each site. Detailed graphs, including control treatments (CC, SC), can be found 613 in Figure S6. Vector plots of variables correlated with the PCO axes are indicated, with $\mathrm{r}>0.5$. 614 Only the genus name is given. Note that scales differ among site plots.

616 Figure 3. Summary of the major species-specific and abiotic variable responses to predation (cf. 617 Table S5). Color code is as in figure 2. Predation effects are presented as fold-changes of the species 618 cover (normal font) and of the numerical abundance (italic). Fold-changes were obtained by 619 comparing the average values of open and control panels with caged/screened treatments. 620 Significant changes are in bold, with numbers in bracket indicating a possible caging effect. "-" 621 indicates that the species is present but with an occurrence too small to make statistical inferences. 622 Following the scale presented, backward shade indicates the average within-site contribution of 623 each taxon/response variable to the community upon open and control panels (i.e., exposed to all 624 predators).

Figure 4. Temporal variation in community structure (PCO) upon panels deployed in August 2016 (trial 1) and March 2017 (trial 2) in each study site. Color code in vector plots are as in Figure 2. 
Fig. 1

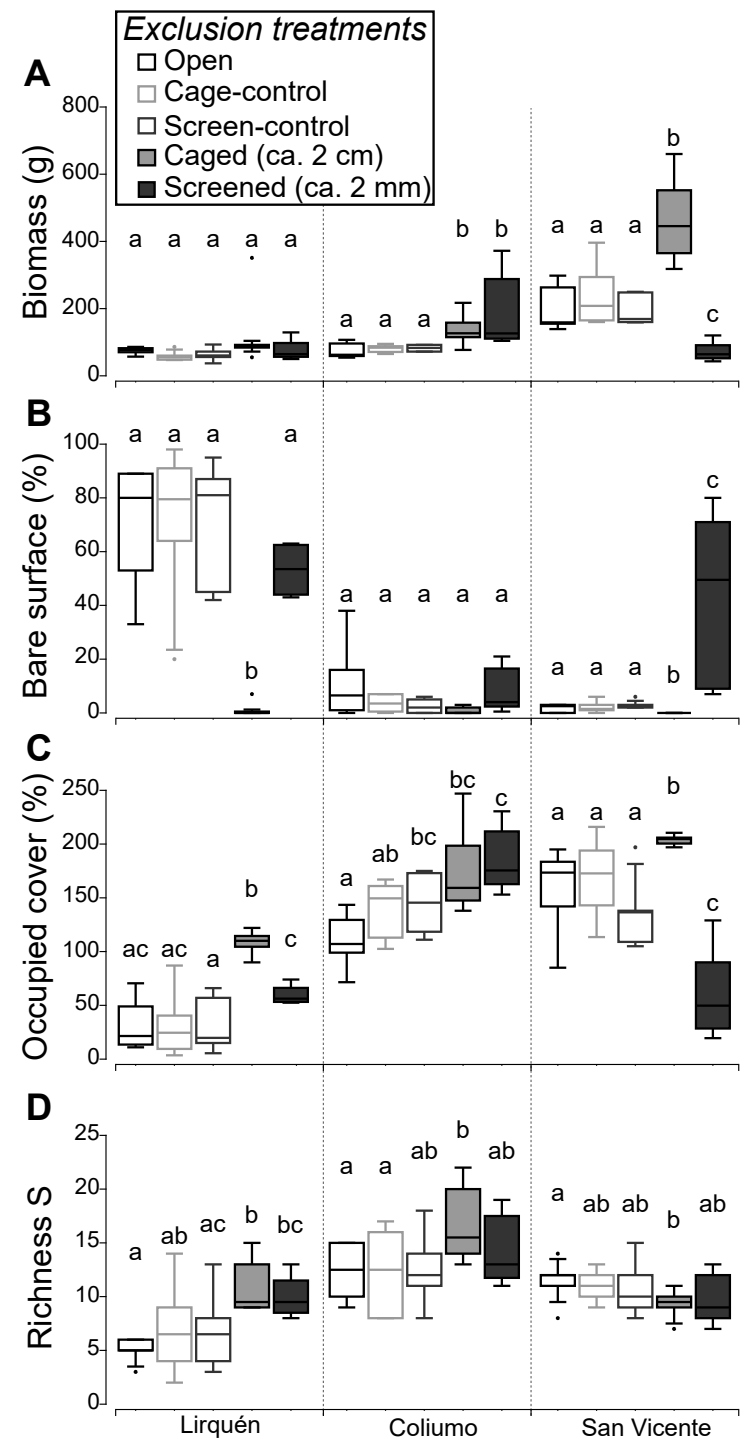


Fig. 2

\section{A. Lirquén}

\section{Exclusion treatments}

\section{- Open $\square$ Cage-control $\diamond$ Screen-control \\ Caged (ca. $2 \mathrm{~cm}$ ) Screened (ca. $2 \mathrm{~mm}$ )}

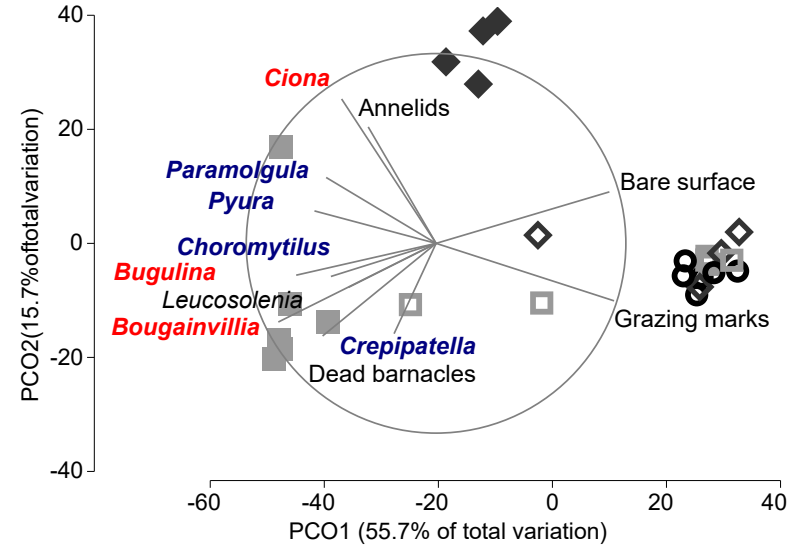

Native Cryptogenic NIS

\section{B. Coliumo}
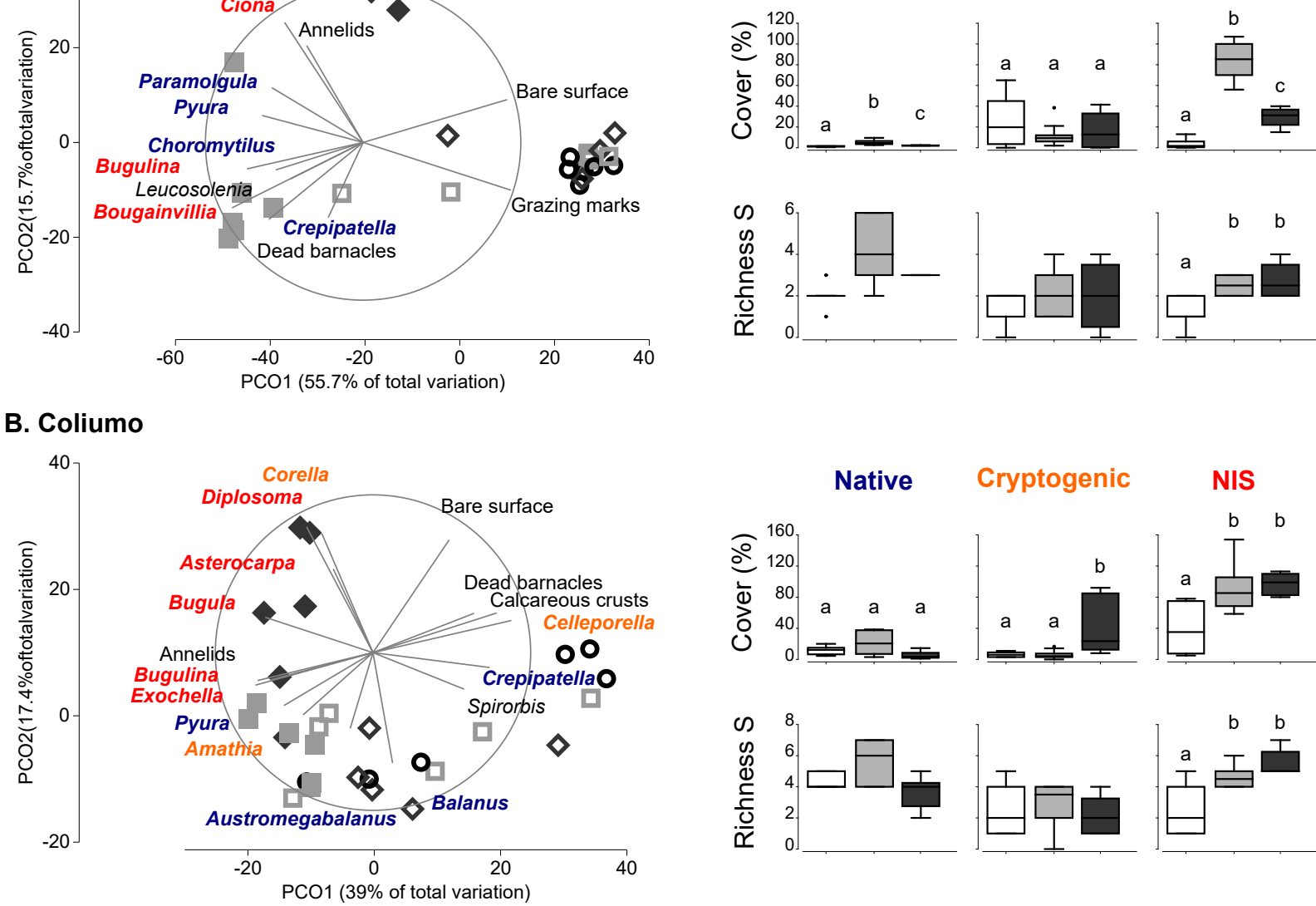

\section{San Vicente}
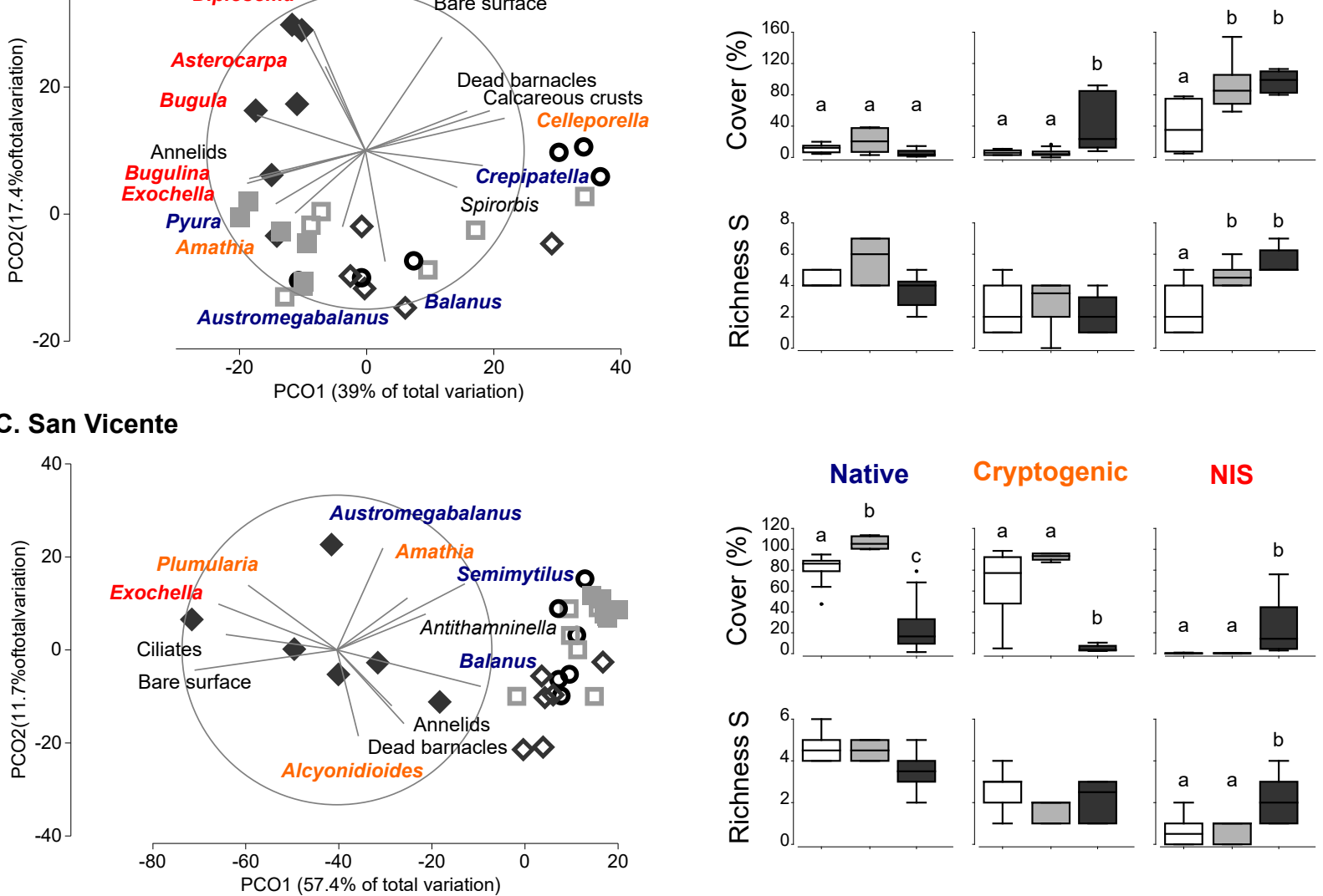


\section{Macropredators effect}

Micro- and macro-

predators effect

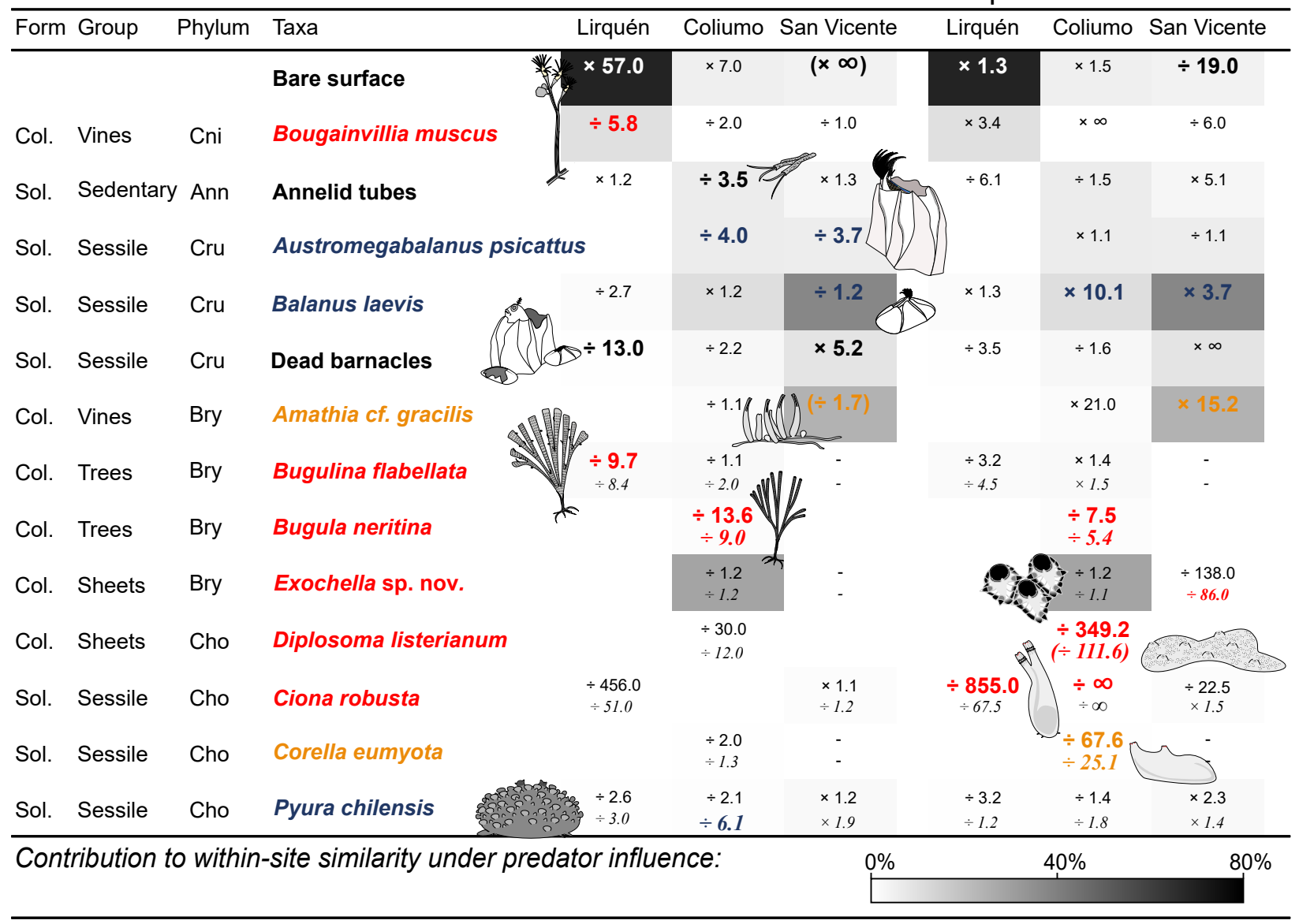


